\title{
La evaluación comprensiva
}

\author{
José Ignacio Antón Pérez
}

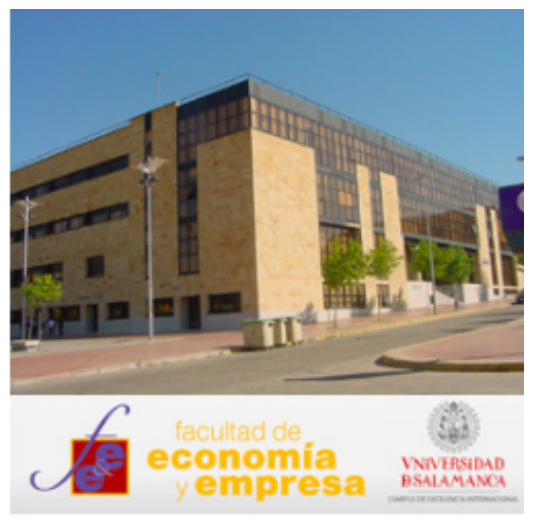

\section{Departamento de Economía Aplicada}

\begin{abstract}
ON EL FIN DE ADAPTAR LA EVALUACión de las enseñanzas impartidas a lo propuesto en el Espacio Europeo de Educación Superior, se pretende con esta práctica introducir en las herramientas de evaluación una pluralidad de elementos de carácter diagnóstico o prospectivo, y formativo que se suman a las herramientas de naturaleza sumativa. Es decir, se realiza lo que hoy en día se conoce como «evaluación comprensiva».

El origen de esta práctica se encuentra en una experiencia de innovación docente (ID2017/109) de la Universidad de Salamanca.
\end{abstract}

La evaluación comprensiva planteada se aplica a la asignatura «Economía del Estado de Bienestar», de carácter obligatorio y perteneciente al $4^{\circ}$ curso del Grado en Recursos Humanos y Relaciones Laborales, que es impartida por el profesor José Ignacio Antón Pérez.

La evaluación prospectiva es aquella con carácter diagnóstico o inicial, que sirve para determinar el punto de partida en el que se encuentra el estudiante.

La evaluación formativa persigue mejorar el proceso de enseñanza-aprendizaje a partir de la existencia de un feedback sobre el desempeño a lo largo del mismo.

La evaluación sumativa se vincula a la evaluación del desempeño al final del proceso enseñanza-aprendizaje. 
Los componentes de la evaluación comprensiva planteada en esta propuesta y su repercusión en la calificación final son los siguientes:

- Test de nivel con el fin de conocer el nivel de conocimientos de los estudiantes (evaluación prospectiva). No influye en la calificación final.

- Test de repaso realizado a través de Studium y examen de ejemplo en el que los alumnos pueden elegir una pregunta, responderla y entregarla al profesor, que se la devolverá con las correcciones pertinentes (evaluación formativa). El test de repaso representa el $10 \%$ de la calificación final. El examen de ejemplo no influye en la nota.

- Comentarios de texto, examen de respuesta múltiple sobre lecturas, examen final de preguntas abiertas de desarrollo y actividades voluntarias (evaluación sumativa). Representan el $90 \%$ de la calificación.

Para llevar a cabo la evaluación formativa resulta especialmente interesante el empleo de rúbricas.

A final de curso se realiza una encuesta de satisfacción a los estudiantes (escala tipo Likert de 1 a 5) sobre el proceso de evaluación realizado, que ha arrojado los siguientes resultados:

- Valoración global de la asignatura: 3,9.

- Valoración de la inclusión de los tres tipos de evaluación: 4,3 .

- Valoración del test inicial: 4,7.

El rendimiento de los estudiantes fue superior al del curso anterior $(2016 / 2017)$, incrementándose

aproximadamente un punto.

Adaptar la docencia al nivel de conocimientos de los estudiantes favorece mejores resultados.

En cuanto a la difusión, la práctica ha sido presentada en eventos de carácter nacional e internacional, y ha dado lugar a un artículo científico.

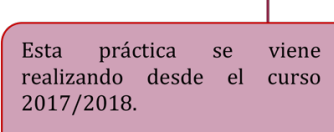

Para más información consultar:

http://ocw.usal.es/cienci as-sociales-1/economiadel-estado-del-bienestar

- Valoración del examen de muestra: 4,9.

- Valoración del test de repaso: 4,8. 